\title{
Prediction of Adult Height in Turner Syndrome
}

David A Price, Michael B Ranke, Kerstin Albertsson-Wikland and Lisbeth C Karlsson on behalf of the KIGS Board

Royal Manchester Children's Hospital (DAP), Manchester, UK, University Children's Hospital (MBR),

Tübingen, Germany and Department of Pediatrics, University of Göteborg (KA-W, LCK), Göteborg, Sweden

Predictions of adult height in girls with Turner syndrome using established methods, projected height (PROJ), predicted height (PRED), and index of potential height (IPH), were compared to a novel method (KIGS):

KIGS (as ht SDS) = ht SDS (using Ranke standards) - BA SDS for CA.

BA SDS for CA was calculated from Greulich and Pyle BAs of 640 untreated girls with Turner syndrome entered into the Kabi Pharmacia International Growth Study. Adult height predictions for 245 girls at onset of growth hormone (GH) treatment (mean $\pm \mathrm{SD}$ ) were $145.5 \pm 6.0 \mathrm{~cm}$ (PROJ), $144.9 \pm 6.4 \mathrm{~cm}$ (PRED), $153.7 \pm 7.2 \mathrm{~cm}$ (IPH), and $145.5 \pm 6.4 \mathrm{~cm}$ (KIGS). 26 girls treated for 3 years with GH alone had increases in height prediction of $8.7 \pm 4.3 \mathrm{~cm}$ (PROJ), $5.6 \pm 5.1 \mathrm{~cm}$ (PRED), $7.2 \pm 6.0 \mathrm{~cm}$ (IPH), and $3.3 \pm 6.4 \mathrm{~cm}$ (KIGS). Height predictions for 15 girls treated with combinations of $\mathrm{GH}$, estrogen and oxandrolone were then compared to their own achieved adult heights: at 2 years into treatment, PROJ, PRED, and IPH already overestimated adult height by $1.8 \pm 2.5 \mathrm{~cm}, 2.5 \pm 1.3 \mathrm{~cm}$, and $13.8 \pm 1.6 \mathrm{~cm}$, respectively, and KIGS underpredicted by $2.5 \pm 1.5$ $\mathrm{cm}$. We conclude that the established methods, especially IPH, tend to overpredict adult height in Turner syndrome and that the KIGS method is more conservative. 